\title{
Leveraging of Reputation through Umbrella Branding with and without Market Power
}

November 8, 2011

\author{
Eric B. Rasmusen
}

\begin{abstract}
The Klein-Leffler model explains how the benefit of future reputation can induce firms to produce high quality experience goods, either in a monopoly or an industry with competing firms. We show that reputation can be leveraged across products, but only by a firm with a monopoly on at least one product. Such a firm, however, may be able to capture the market for a competitive product by using umbrella pricing to make higher quality more credible than for firms without a monopoly base. Such monopoly extension increases social welfare, and can even benefit consumers, despite the increase in price. The expanding monopolist does not need to use bundling, and consumers are left better off, but otherwise this looks like classic monopoly leverage.

Rasmusen: Dan R. and Catherine M. Dalton Professor, Department of Business Economics and Public Policy, Kelley School of Business, Indiana University. BU 438, 1309 E. 10th Street, Bloomington, Indiana, 47405-1701. (812) 855-9219. Fax: 812-855-3354. erasmuse@indiana.edu, http://www.rasmusen.org.

This paper: http://www.rasmusen.org/papers/umbrella.pdf.

Keywords: product quality, umbrella branding, economies of scope, reputation.

I would like to thank Yiquan Gu, Jeanine Miklos-Thal, David Myatt, Kevin Seok, Claire Zheng, and participants in talks at the Indiana BEPP brown bag lunch, the University of Louisville, and the 7th International Industrial Organization Conference for their comments, and Nuffield College, Oxford for its kind hospitality while this was begun.
\end{abstract}




\section{Introduction}

Umbrella branding is the practice of labelling more than one product under a single brand name. Kellogg's breakfast cereals and General Electric household appliances are natural umbrella brands since the products are similar, but sometimes a brand will be applied to wildly dissimilar products. Vuarnet sells sunglasses, skis, pens, and clothing. Virgin went from being a brand of phonograph record to a brand of airline services, vodka, and soft drinks. As Andersson (2002) notes, the founder of Virgin, Richard Branson, said "Consumers understand that all the values that apply to one product- good service, style, quality, value and fair dealing - apply to the others.(Time Magazine, No. 26, June 1996.) Even when the products are more similar, one may ask why one might think that quality in one product under an umbrella brand should be linked with a process that has distinct production lines. The Korean company LG uses the LG brand for a wide variety of appliances and electronics. Its head of brand marketing for the UK said, "The LG logo and motto are strong icons that connect everything together. Consumers take those beliefs and brand equity with them to the checkout as a source of reassurance." Sony is similar, one executive saying, "Everything we do now runs under a common identity; people know Sony and they believe the brand values of the master brand. Therefore, they feel reassured about what they are buying. The umbrella branding gives us a meaning, not just a logo."(“Talking shop: Umbrella branding," Marketing Week, (Nov. 12. 2009), http: //www.marketingweek.co.uk/talking-shop-umbrella-branding/3006453.article.)

Reputation can solve a problem of either adverse selection - to show which firms have committed to high quality in the past- or moral hazard - to show that a firm will produce high quality even without commitment. The present paper will be about moral hazard. Klein \& Leffler (1981) explained how the threat of loss of reputation can make firms produce high quality at high cost even if consumers cannot observe quality until after they purchase. The firm could make a one-time high profit in the present if it cheated consumers with low quality, but that gain is less valuable than the smaller but permanent flow of profits from future sales it 
obtains if it maintains a good reputation. The idea applies to both monopolies and to competitive firms, but there are positive profits even in a competitive industry of this kind, because the firms must have future profits to lose if they deviate to low quality.

The Klein-Leffler model has been formalized as a model of infinitely repeated moral hazard, with firms deciding between low and high quality in each period. ${ }^{1}$ The Folk Theorem tells us that this game has an infinite number of equilibria. The extremes of these, however, are an equilibrium in which the one-shot game's bad equilibrium with low quality is repeated and a reputation equilibrium in which firms produce high quality in each period. In the reputation equilibrium, each firm is unwilling to reduce its quality because it would lose the future flow of profits, and unwilling to reduce its price because to do so would tell consumers that it had too little incentive to maintain quality.

When a firm has a reputation for quality in producing one good, it is natural to ask whether it can leverage that reputation into the production of other goodsumbrella branding. If reputation is based on adverse selection-incomplete information on characteristics rather than choices - the question is what links the two products, the need to use some common high-quality technology, or the producer's intrinsic honesty. Wernerfelt (1988) builds an adverse selection model of this kind, to show the advantage of umbrella branding for a firm with market power and exogenous quality. Choi and Scarpa (1992) show how reputation extension can lead to credible spatial pre-emption in a location model.

If, as in the Klein-Leffler model, the reputation is based on the firm's incentives to choose high quality, then the incentive compatibility constraints for the different products would interact in a way similar to what Bernheim and Whinston (1990) found in the incentives to cheat on collusion when oligopolists interact in more than one market. Andersson (2002) extended the Klein-Leffler model to multiple products produced by a monopoly. He demonstrated what will be our Proposition

\footnotetext{
${ }^{1}$ A non-game-theoretic formalization is the model in Shapiro (1983), which assumes that consumers believe a firm's product quality is the same as it was in the previous period.
} 
2: that it is easier for a monopolist to maintain high quality when it sells more than one product. Cabral (2009) shows the same in a model with imperfect observability of quality by consumers and notes that asymmetry of the two products is not key to the benefits of branding.

An earlier model of imperfect observability and umbrella branding is Cabral (2000). Dana \& Spier (2009) use a Klein-Leffler model with imperfect observability of quality by consumers in which the low-quality product "fails" only with some probability. In their model, a consumer who buys more products from a firm becomes a better monitor of its behavior because he collects more signals of quality. Miklos-Thal (2010) is also in this tradition and shows that a firm introducing a new product has incentive to use umbrella branding for a product whose quality is similar to the old one's because it helps sell more of the old product as well as of the new. In such a model, mistakenly introducing a bad new product will hurt sales of the old. An example of this is studied in Swaminathan, Fox \& Reddy (2001), which looks at the case of a food product with a large market share that introduced a new product under the same brand name that turned out to be a failure and was withdrawn. Sales of the original product suffered.

In Rotemberg (2010), some firms are altruistic and some consumers take a firm's perceived altruism into account in their purchase decisions. This means that a firm that produces a low-quality new product will be punished by lost consumer sales even on its old product.

Our focus on market structure distinguishes this paper from the other papers in the Klein-Leffler tradition and, indeed, those on umbrella branding generally. Choi (1998) builds a model in which a firm launches a new product each period that it then sells for two periods. The firm can choose either high or low quality, and as in the Klein-Leffler model, future profits incentivize present quality, but with many products over time instead of one. Choi (2003) follows up on this with attention to the implications for the timing of new products. Hakenes and Peitz (2008) look at a two-period model in which a monopolist makes a one-time quality choice and low-quality products fail with some probability. They show that um- 
brella branding affects the monopolist's quality choice in interesting ways: one of the branded products might be sold at a loss, and quality might be too low instead of too high. Cai and Obara (2006) also look at once-and-for-all quality choices, and assume that the quality chosen is the same for all products.

This existing literature has looked at umbrella branding by monopolies- that is, by firms with market power. It does not look at what will be our main focus here: the contrast between competitive and monopolized markets. We will show that although competitive firms can have profitable reputations for quality - the key insight in Klein \& Leffler (1981) - they cannot leverage these reputations into other markets, unlike monopolies. As a result, a monopoly may, under particular circumstances, be able to capture a competitive market by introducing umbrella branding and this capture can aid consumers despite the higher prices it brings. This can be shown in a model simple enough to bring out the intuition behind the results.

I will also make several overlooked points about incentive compatibility in the one-product Klein-Leffler model when perceptions of low quality do not entirely close down a market: that the conditions for reputation viability for monopolized and competitive industries are the same, that an exogenous worsening in the level of low quality can increase equilibrium welfare, and that a monopolist may wish to surrender its market power over the production of low-quality goods.

Since we will be looking at the ability of a monopolist to leverage its reputation to take over a competitive market, this model could also be seen as part of the literature on foreclosure that is surveyed by Rey, Seabright \& Tirole (2001) and Rey \& Tirole (2006). Foreclosure can occur for many reasons. Perhaps the reason closest to that in the present paper is in the tying model of Whinston (1990), in which a monopoly ties its monopolized product with a competitive product to increase the aggressiveness of its pricing in the competitive market and drive out rivals there. That model will be discussed in more detail once the present paper's model has been laid out. 


\section{Single-Product Equilibrium under Competition and Monopoly}

\section{Assumptions}

One or more firms produce a single good, which has either low or high quality. Each firm chooses its own quality anew each period. All firms have a marginal cost of $c$ for the low-quality version of the product and $(1+\gamma) c$ for the high quality version, with $\gamma>0$.

We will look at both monopoly and competition. In the monopoly case, the monopolist chooses the price. In the competitive case, a unit interval continuum of firms engage in Bertrand price competition.

Consumers lie on a continuum of length $x$. Consumers are identical. Each wishes to buy one unit of the good and is willing to pay up to $v$ for low quality or $(1+\theta) v$ for high quality, with $\theta>\gamma$ so that producing high quality adds more to value than to cost. Consumers simultaneously decide which firm to patronize or whether not to buy at all. We will assume that if consumers are indifferent among a set of firms they spread evenly across those firms. A firm's quality in a given period is unobservable before purchase, but becomes common knowledge after purchase. The discount rate is $r$, payments occur at the end of periods, and there are an infinite number of periods.

Thus, at the start of a period, firms choose prices and qualities. Consumers then decide whether and where to buy. An interval of time passes, and at the end of the period firms pay the cost of production, consumers pay the firms, receive the product, and everyone learns the quality the products that were purchased. The next period then begins with new decisions by firms about prices and qualities.

We will assume that

$$
(1+\theta) v-(1+\gamma) c>0,
$$

which says that purchasing a high-quality product at cost is better for the consumer than not buying at all. 
If $v>c$ we will say that low quality is viable: it is more efficient for consumers to buy low quality than not to buy at all. If $v<c$ we will say that low quality is unviable.

These assumptions imply that high quality is efficient. High quality's consumer surplus is higher than low quality's if

$$
(1+\theta) v-(1+\gamma) c>v-c .
$$

If $v-c>0$, then inequality (2) is implied by our assumption that $\theta>\gamma$. If $v-c<0$, then (2) is also true, because its left-hand-side is positive by assumption (1) and its right-hand-side is negative.

\section{The General Characteristics of Equilibrium for a Single Product}

Infinitely repeated games such as this one have an infinite number of subgame perfect equilibria. Depending on player beliefs, a vast array of behaviors can be constructed as occuring in equilibrium. We will focus on two equilibria: a pessimistic equilibrium in which quality is low, and an optimistic equilibrium in which quality is high. The defense for these equilibria is that their beliefs are simple and plausible. ${ }^{2}$ I will describe the equilibria here and derive the details afterwards.

The pessimistic equilibrium. Firms produce low quality and charge $p=c$ if the industry is competitive and $p=v$ if it is monopolized. Consumers purchase at the lowest available price if it is less than $v$ and do not purchase otherwise. If a firm deviates from equilibrium, consumers still believe it will produce low quality in the future.

\footnotetext{
${ }^{2}$ This is not a game of incomplete information, so most belief refinements would have no bite. Forward induction will not either, since after any deviation, any pattern of future behavior over a finite number of periods remains part of some equilibrium compatible with the deviation.
} 
The optimistic equilibrium. Firms produce high quality in equilibrium. If, out of equilibrium, they have ever produced low quality, they thereafter produce low quality. In a competitive market the equilibrium price is $p=c+(1+r) \gamma c$, and in a monopolized market it is $p=(1+\theta) v$. If consumers believe the quality is high, they purchase at the lowest available price if it is less than $(1+\theta) v$ and do not purchase at all otherwise. If consumers believe the quality is low, they purchase at the lowest available price if it is less than $v$ and do not purchase at all otherwise. Out of equilibrium, if consumers observe a firm charging less than the equilibrium price, they believe it has chosen low quality; otherwise, they believe it has chosen high quality.

The pessimistic equilibrium always exists, although if $v<c$ low quality is unviable and no sales will be made.

The optimistic equilibrium may or may not exist, depending on parameter values and market structure, as we will next explain.

\section{The Equilibrium in a Competitive Industry}

The pessimistic equilibrium is simply repetition of the one-shot game's equilibrium. If $v>c$, so low quality is viable, firms produce quantity $x$ with low quality and charges $p=v$ because low quality is less costly for them to produce and a deviation to high quality would not affect consumer beliefs. If $v<c$, no trade at all takes place, since consumers are unwilling to pay even the cost of a low-quality good.

In the optimistic equilibrium, the price exceeds marginal cost, because sellers require an inducement to forgo earning short-term profits by producing low quality. Let us call the minimum necessary price that makes high quality a possible equilibrium outcome the "Klein-Leffler price" and denote it by $p^{*}$. This price will equal

$$
p^{*}=c(1+\gamma)+r \gamma c=c+(1+r) \gamma c .
$$

which is the marginal cost of a high-quality good, $c(1+\gamma)$, plus the extra cost of 
high quality times the discount rate. The alternative expression $c+(1+r) \gamma c$ is included because it will be convenient later.

This value of $p^{*}$ is derived by equating a firm's payoffs from low and high quality. In any period, the firm can choose either high or low quality. The KleinLeffler price equates the present discounted value of the profit from high quality for the infinite periods that it continues

$$
\pi(\text { high quality })=\frac{(p-c(1+\gamma)) x}{r},
$$

to the present discounted value of the one period of profits from low quality followed by zero profits:

$$
\frac{(p-c) x}{1+r}
$$

Equating equations (4) and (5) and solving for $p$ yields the Klein-Leffler price $p^{*}$ in definition (3).

For the optimistic equilibrium to exist requires that consumer prefer buying a product believed to be high quality at price $p^{*}$ instead of a product believed to be low quality at price $c$, its cost. Consumer surplus from the high-quality good is

$$
(1+\theta) v-p^{*}=(1+\theta) v-[c(1+\gamma)+r \gamma c] .
$$

Consumer surplus from the low-quality good priced at marginal cost is $v-$ $c$. We need the consumer surplus from high quality to be greater than from low quality:

$$
(1+\theta) v-[c(1+\gamma)+r \gamma c]>v-c .
$$

Simplifying (7) yields the condition for an optimistic equilibrium to exist in a competitive market:

$$
\theta v \geq(1+r) \gamma c
$$


If (8) is true we will say that the high-quality product is viable in a competitive market. Otherwise, the optimistic equilibrium fails to exist, because though consumers are willing to pay the cost of high quality (so $(1+\theta) v \geq(1+\gamma) c)$, they are unwilling to pay the price necessary to give firms incentive to produce it (so $\left.(1+\theta) v<p^{*}\right)$.

Let us now check that no player would wish to deviate from the optimistic equilibrium. In equilibrium, the consumer's strategy is to believe the product is high quality unless some firm has already deviated, and to buy the product from the cheapest firm whose price is between $p^{*}$ and $(1+\theta) v$. If the consumer observes a firm with price less than $p^{*}$, he will not buy from that firm, because his out-ofequilibrium belief is that the product's quality is low, and the viability condition (5) tells us that his payoff is higher from buying high quality at $p^{*}$. Thus, no consumer will deviate.

Firms charge $p^{*}$ in equilibrium and earn the payoff in equation (4) because the quantity demanded, $x$, is split evenly across the unit interval of firms. Any firm that deviated to a higher price would sell nothing in that period, and so would reduce its payoff. Any firm that deviated to a lower price would be believed to have low quality in that period and thereafter. This is dominated by charging $p^{*}$ and deviating to low quality, which results in the one period of positive profit shown in equation (5) when we derived $p^{*}$. In subsequent periods, when the firm is believed to produce low quality, it is clear no consumer will buy if $v<c$. If $v>c$, a consumer could earn surplus buy buying low quality, but the viability condition (5) tells us that buying high quality at $p^{*}$ is preferable. Thus, no firm will deviate.

Even though firms are competitive they earn positive profit. In some reputation models it is assumed that firms incur a fixed entry cost so that in equilibrium the overall profit of the positive operating profit minus the fixed cost equals zero. Here, the profit is split among the firms on the unit interval.

There exist other high-quality equilibria in this game if we change the outof-equilibrium beliefs. The beliefs in the optimistic equilibrium say that if firms 
deviate to charge less than $p^{*}$ they lose their reputation and are believed to have produced low quality. This could be replaced by the belief that if firms deviate to charge less than $p^{\prime}$ they have produced low quality, where $p^{\prime}>p^{*}$ is a price such that consumers still prefer buying high quality to buying low at marginal cost. In that case, all firms would charge $p^{\prime}$. The choice of the level of $p^{\prime}$ in consumer beliefs is arbitrary, and the equilibrium requires consumers to believe that a firm which has deviated to the price $p^{*}$ has also deviated to low quality. This kind of belief can be ruled out by an equilibrium dominance argument: since the deviating firm would reduce its payoff by deviating from $p^{\prime}$ and high quality to $p^{*}$ and low quality, but would increase its payoff if it deviated to $p^{*}$ and high quality and consumers believed the quality was high, consumers should adopt the second belief. Then, the only high-quality equilibrium is at a price of $p^{*}$, because firms can compete price down from $p^{\prime}$ to $p^{*}$ without losing their incentive to produce high quality. Any lower price would remove that incentive.

\section{The Equilibrium for a Monopoly}

We next consider a market with just one firm. Again, there is a pessimistic equilibrium and an optimistic one. The pessimistic equilibrium is much as in the competitive case: consumers expect low quality, and the firm chooses low quality because it is cheaper and its actions cannot change consumers' minds. In the optimistic equlibrium, there is again a price $p^{*}$ at which the firm is willing to choose high quality, found as follows. The monopoly's lifetime profit per unit from selling high quality at $p *$ is the same as in equation (4). If the consumption value of low quality is less than marginal cost $(v<c)$, so consumers do not purchase at all if they believe quality is low, then the monopoly's profit from deviating to low quality is the same as in equation (5) because after the deviation its sales will cease. Thus, if $v<c$ then the "monopoly Klein-Leffler price," $p^{*}$ (monopoly), will equal the competitive Klein-Leffler price $p^{*}$ that was previously defined.

If $v>c$, on the other hand, consumers will continue to buy even if they expect low quality, though they will not be willing to pay as high a price. The monop- 
olist's profit from deviating to low quality then has two parts, the one-time large gain from when consumers are fooled into paying the high-quality price and a steady stream thereafter of positive though lower profits from charging $v$ for low quality. Instead of expression (5), the monopoly's payoff is

$$
\pi(\text { low quality, monopoly })=\frac{(p-c) x}{1+r}+\frac{(v-c) x}{(1+r) r} .
$$

Comparing the equilibrium payoff from high quality, an expression like equation (4) but with a possibly different value of $p$, with the deviation payoff in equation (9) yields the following incentive compatibility constraint for the firm:

$$
\frac{(p-(1+\gamma) c) x}{r} \geq \frac{(p-c) x}{1+r}+\frac{(v-c) x}{(1+r) r} .
$$

Making the incentive compatibility constraint binding and solving for $p$ yields the quality-guaranteeing price in the first line of equation (11) below, which is higher than the competitive-industry price in equation (3). Putting together the two possibilities for the monopoly Klein-Leffler price, we obtain:

$$
\begin{array}{rlrl}
p^{*}(\text { monopoly }) & =v+(1+r) \gamma c & & \text { if } v>c \\
& =c+(1+r) \gamma c=p^{*}(\text { competitive }) & \text { if } v<c
\end{array}
$$

Thus, if the low-quality good would be rejected by consumers even at a low price, a monopoly and a competitive industry have the same quality-guaranteeing price, but otherwise the monopoly's is higher. The intuition behind this is that when consumers value low-quality more, the monopoly, unlike the competitive firms, does not see its profit flow fall all the way to zero after deviating to low quality. With a less severe punishment in its incentive compatibility constraint, the monopoly needs a bigger reward for good behavior. 
Equation (11) says that when $v>c$ the monopoly Klein-Leffler price is greater than the competitive Klein-Leffler price. One might think that this means that there exist parameter values for the quality premium $\theta$ high enough for high quality to be viable for a competitive industry but not for a monopoly. That is false, as Proposition 1 tells us.

Proposition 1: Whenever parameter values make high quality viable under competition they also make it viable under monopoly.

Proof. If $v<c$ then the Klein-Leffler price is the same for the monopoly and the competitive industry, so the proposition is obvious. Let us therefore focus on $v \geq c$.

We found in inequality (8) that for high quality to be viable in a competitive market when $v \geq c$ requires that

$$
\theta v \geq(1+r) \gamma c .
$$

For high quality to be viable in a monopoly market when $v>c$ requires that the monopolist not deviate to low quality and its still-positive profits and that the consumer not deviate to purchasing nothing instead of high quality. By construction $p^{*}($ monopoly $)$ is the minimum price that will induce the firm to choose high quality instead of deviating. Thus, the question is whether the consumer is willing to pay $p^{*}$ (monopoly) instead of buying nothing. He will if this price is less than his value for high quality, which requires

$$
(1+\theta) v \geq p^{*}(\text { monopoly })=v+\gamma(1+r) c .
$$

Inequality (13) is true if and only if

$$
\theta v \geq(1+r) \gamma c,
$$

which is therefore our condition for an optimistic monopoly equilibrium to exist. 
This, however, is identical to the viability condition for the competitive industry, inequality (12). Whenever the parameter values allow a monopoly optimistic equilibrium to exist, they also allow a competitive optimistic equilibrium to exist.

Proposition 1 is somewhat unexpected because we had found that in the case when the consumer would buy low quality if that were the only alternative (when $v>c$ ) the quality-guaranteeing price is higher for the monopolist. Yet Proposition 1 tells us that the viability problem of that price being so high that no equilibrium with high quality exists is no more severe than for a competitive industry. The reason is that the most tempting deviation has a different character for the monopoly. For the monopoly, what matters is whether the firm is tempted to deviate to low quality to obtain a one-time gain and then begin selling low quality at a low but profitable price. For the competitive industry, that is not the binding constraint. Rather, what matters is whether consumers would switch from a firm selling high quality at $p^{*}$ to a firm selling low quality at $c$. Thus, we cannot simply compare the quality-guaranteeing prices in the two industry structures.

That explanation, however, leaves us with the puzzle as to why two such different constraints yield exactly the same parameter range for viability. The monopoly is comparing high quality's steady profit flow to the combination of a one time windfall profit plus low quality's steady flow. In the competitive industry, consumers are comparing the utility flows from high quality and from low quality - different players, and different kinds of payoff streams. The resolution to that puzzle is that in the competitive industry, the high, quality-guaranteeing price yields a profit flow to a firm that has a capitalized value equal to the one-time gain from deviating to low quality. The monopoly compares the capitalized value of the high-quality social surplus (call it $X$ ) to the combination of the low-quality social surplus (Y) plus the one time gain from cheating (Z), to see if $X>Y+Z$. The consumers compare the capitalized value of the high-quality social surplus $(X)$ minus the capitalized value of the steady quality-guaranteeing price premium (which equals the one-time gain from cheating, $Z$ ) to the social surplus from low quality (Y), to see if $X-Z>Y$. The inequalities end up being equivalent. 
Proposition 1 is important for us to be able to go on to explore leveraging monopoly by umbrella pricing. It shows that if leveraging works, it is not because even in a single market a monopoly has more incentive to produce high quality than a competitive firm.

We will take this opportunity to make two observations about quality viability that do not seem to be in the literature.

Observation 1. Suppose a competitive market is viable for low quality but not for high quality. If the the low-quality product becomes worse ( $v$ falls) while the high-quality product does not $((1+\theta) v$ stays the same) social welfare can rise because high quality may become viable.

Proof. Return to the viability condition in (7):

$$
(1+\theta) v-[c(1+\gamma)+r \gamma c]>v-c .
$$

If this inequality is false, so high quality is not viable, then it can be made true if the value of the low-quality product, $v$ on the right-hand-side, can be reduced while keeping the value of the high-quality product on the left-hand-side, $(1+\theta) v$, constant. This unilateral worsening of the value of low quality is to be interpreted as a simultaneous reduction in $v$ and an increase in $\theta$ that keeps $(1+\theta) v$ unchanged.

Once the viability condition is satisfied, the optimistic equilibrium again becomes possible. Since by assumption high quality yields higher social welfare than low quality, the result is that the worsening of low quality has raised social welfare.

Viability depends on the value added of high quality over low quality because it is based on satisfying the incentive compatibility constraint for producing high quality. An unviable market can become viable either by increasing the highquality good's value or by reducing the low-quality good's. Reducing the lowquality good's value while keeping the high-quality good's the same is equivalent 
in our notation to reducing $v$ while increasing $\theta$ enough to keep $(1+\theta) v$ constant. By assumption, high quality generates greater social welfare, so this would be an improvement.

Both a competitive and a monopolistic industry would increase profits by making high quality viable in this way, and social surplus would rise. Whether consumer surplus would rise is less clear. In the competitive industry, consumers would have positive payoffs even in the pessimistic equilibrium if low quality is viable. Worsening the low-quality product could eliminate any surplus from it while reducing $p^{*}$ to just slightly below $(1+\theta) v$, the consumer's value. In this model's monopoly case, on the other hand, consumers earn zero surplus in either the pessimistic or the optimistic equilibrium, so the product-worsening strategy would affect only the firm.

The benefit of quality reduction is best known in the context of price discrimination. Deneckere \& McAfee (1996). show how a seller's profits can rise if it reduces the quality of one of two goods it is offering. The reason in price discrimination, however, is completely different, though both involve incentive compatibility constraints. In price discrimination, it is because of the need to reduce the temptation of the type of consumer who more prefers high quality to deviate to buy the cheaper low-quality good. In reputation maintenance, it is because of the need to reduce the temptation of the seller to deviate to selling low quality.

The atomistic firms themselves could hardly reduce the value of low-quality goods, but that might be accomplished by government intervention. The government might relax anti-fraud laws or reduce minimum quality standards such as building codes. Or, the reduction might happen exogenously.

A monopoly, however, could have another tool available for generating viability: giving away some of its market power, which leads to Observation 2 . 
Observation 2. If the monopolized market is unviable for high quality, the monopolist may be able to profitably make it viable by allowing free entry into production of the lowquality good.

Proof. We start with the premise that $v>c$. The monopolist's quality-guaranteeing price is $p^{*}=v+(1+r) \gamma c$ when $v>c$, which was derived by comparing the profits from high quality with the profits from deviating to permanently selling low quality. The quality-guaranteeing price derived by deviating to not producing at all after the period of cheating was $p^{*}=c(1+\gamma)+r \gamma c$, which is lower because $v>$ $c$. This was derived for the case of $v<c$, but it applies equally well if permanent deviation profits are zero because the low-quality market is competitive. Thus, by making the low-quality market competitive, the monopolist is able to credibly promise high quality at a lower price than before.

We must still ask whether the monopolist's profits are higher after switching to high quality in this way. The monopolist was earning positive profits before the switch, and the fact that social surplus rises with is not determinative because the monopolist does not obtain the entire social surplus. It must face competition from low-quality firms charging $c<v$ for an item with value $v$, so it cannot take away all the consumer surplus by setting the high-quality price at $(1+\theta) v$. Rather, the monopolist's price $p$ must make the consumers indifferent between its high quality and the competitive low quality, so

$$
(1+\theta) v-p \geq v-c
$$

and $p=c+\theta v$. Using this price for the profits from the strategy of opening up low quality to competition, the monopolist's payoff is

$$
\frac{p-(1+\gamma) c}{r}=\frac{c+\theta v-(1+\gamma) c}{r}=\frac{\theta v-\gamma c}{r}
$$

The profits from keeping the monopoly on low quality are $\frac{v-c}{r}$. Since $v>c$ 
and $\theta>\gamma$ (from the initial assumptions of the model), it is possible that

$$
\frac{\theta v-\gamma c}{r}>\frac{v-c}{r}
$$

and profits are higher from opening up competition in low quality if $\theta$ is large enough relative to $\gamma$. Since high quality is initially unviable, however, we know that the gap between $v$ and $c$ is constrained by the viability condition, $\theta v<(1+$ $r) \gamma c$. If this were made an equality, making $\theta$ as big as possible, we could substitute for $\theta v$ in (17) to get the condition

$$
\frac{(1+r) \gamma c-\gamma c}{r}>\frac{v-c}{r}
$$

This condition is true if $r \gamma c>v-c$. Thus, there is a range of parameters for which the monopolist would like to open up low quality to competition.

Observation 2 is true because if the monopoly can allow free entry into producing the low-quality good (perhaps by freely licensing a patent), it eliminates any profits it could earn by producing low quality. As a result, its quality-guaranteeing price would drop, and it could credibly sell high quality. Consumers would realize that the monopolist no longer is so tempted to deviate to low quality, since its future profits in that market would become zero.

Having looked at viability when there is only one good, let us now proceed to viability when there are two goods and umbrella pricing becomes possible.

\section{Umbrella Pricing: Monopoly}

We will now let there be two products, subscripted $i$, with possibly differing parameters $v_{i}, \gamma_{i}, \theta_{i}, c_{i}$, and $x_{i}, i=1,2$. Firms choose the quality of each product separately. We will use $K_{i}$ as an indicator variable, where $K_{i}=1$ if $v_{i} \geq c_{i}$ so that low quality for product $i$ is viable, and $K_{i}=0$ if $v_{i}<c_{i}$.

First, consider what happens if a monopoly firm sells both products. If both 
products are viable, the firm will sell them at prices $\left(1+\theta_{1}\right) v_{1}$ and $\left(1+\theta_{2}\right) v_{2}$ for high quality. It cannot do better by using cross-subsidization. If neither is viable, the firm would sell either nothing or low quality.

Suppose next that high quality for product 1 is strictly viable but for product 2 it is unviable. This means that

$$
\left(1+\theta_{1}\right) v_{1}>p_{1}^{*}(\text { monopoly })=c_{1}+(1+r) \gamma c_{1}+K_{1}\left(v_{1}-c_{1}\right)
$$

and

$$
\left(1+\theta_{2}\right) v_{2}<p_{2}^{*}(\text { monopoly })=c_{2}+(1+r) \gamma c_{2}+K_{2}\left(v_{2}-c_{2}\right)
$$

Note that if $K_{i}=0$ then the monopoly Klein-Leffler price is $c_{i}+(1+r) \gamma c_{i}$, while if $K_{i}=1$ it is $v_{i}+(1+r) \gamma c_{i}$, as we found earlier in the single-product model.

In this case, if the market structure consisted of monopoly 1 for product 1 and monopoly 2 for product 2 , each restricted to producing one product, monopoly 1 would produce high quality and monopoly 2 would either not produce at all or produce low quality.

A two-product monopolist might be able to produce both products at high quality, however, if consumers believe that a deviation to low quality for product 2 implies the firm will produce low quality for product 1 in the future also. We will call these "umbrella beliefs." These beliefs cannot be justified by standard equilibrium refinements, but they are simple and represent a good benchmark case for showing what happens when reputation links two markets. They are the kind of beliefs that seem to have been present in the case Swaminathan, Fox \& Reddy (2001) study of a food product whose sales suffered after the launch and later withdrawal of a new product under the same name.

Umbrella beliefs lead to Proposition 2, which is also what Andersson (2002) found in his model of linked beliefs (and is similar to the result in Cabral (2009) on multi-product monopoly). 
Proposition 2: A monopoly selling two products can for some parameter values maintain high quality for each when two monopolies each selling one product cannot.

Proof. The two-product monopolist's post-entry profit from producing both products with high quality is

$$
\frac{\left(\left(1+\theta_{1}\right) v_{1}-\left(1+\gamma_{1}\right) c_{1}\right) x_{1}}{r}+\frac{\left(p_{2}-\left(1+\gamma_{2}\right) c_{2}\right) x_{2}}{r},
$$

where product 1 is sold at the high-quality monopoly price and product 2 is sold at some price $p_{2}$ as yet unspecified. The most profitable deviation payoff is from deviating to low quality for both products for one period and then continuing to sell with low quality in any market for which low quality is viable. Thus, the payoff for each product is composed of one term for the profits from the one opportunistic period plus a second term for the profits from succeeding periods if low quality is viable for that product.

$$
\frac{\left(\left(1+\theta_{1}\right) v_{1}-c_{1}\right) x_{1}}{1+r}+\left(K_{1} x_{1}\right) \frac{1}{1+r} \frac{v_{1}-c_{1}}{r}+\frac{\left(p_{2}-c_{2}\right) x_{2}}{1+r}+\left(K_{2} x_{2}\right) \frac{1}{1+r} \frac{v_{2}-c_{2}}{r} .
$$

The profit from high quality is at least as high as from deviation if expression (21) is greater than expression (22), which is true if

$$
\begin{aligned}
& \left.[1+r]\left[\left(1+\theta_{1}\right) v_{1}-\left(1+\gamma_{1}\right) c_{1}\right) x_{1}\right]-r\left[\left(1+\theta_{1}\right) v_{1}-c_{1}\right] x_{1}-K_{1}\left(v_{1}-c_{1}\right) x_{1}> \\
& r\left(p_{2}-c_{2}\right) x_{2}-(1+r)\left(p_{2}-\left(1+\gamma_{2}\right) c_{2}\right) x_{2}-K_{2}\left(v_{2}-c_{2}\right)
\end{aligned}
$$

that is, if

$$
\left[\left(1+\theta_{1}\right) v_{1}-\left[1+(1+r) \gamma_{1}\right] c_{1}-K_{1}\left(v_{1}-c_{1}\right)\right] x_{1}>\left[-p_{2}+\left(1+(1+r) \gamma_{2}\right) c_{2}-K_{2}\left(v_{2}-c_{2}\right)\right] x_{2}
$$

so $p_{2}$ must at least equal the critical price $\tilde{p_{2}}$ that solves the last equation as an equality, a price that is always less than the stand-alone monopoly Klein-Leffler 
price $p_{2}^{*}($ monopoly $)$ :

$$
\tilde{p_{2}}=\left[1+(1+r) \gamma_{2}\right] c_{2}-K_{2}\left(v_{2}-c_{2}\right)-\left(\frac{x_{1}}{x_{2}}\right)\left(\left(1+\theta_{1}\right) v_{1}-\left(1+(1+r) \gamma_{1}\right) c_{1}-K_{1}\left(v_{1}-c_{1}\right)\right)
$$

The question is whether $\tilde{p_{2}}<p_{2}^{*}$ (monopoly). If it is, then the two-product monopolist will be able to credibly produce high quality for some parameter ranges where the single-product monopolist could not.

The stand-alone monopoly price is $p_{2}^{*}$ (monopoly) $=c_{2}+(1+r) \gamma c_{2}+K_{2}\left(v_{2}-c_{2}\right)$ from equation (20). Thus, what must be shown is that the term multiplied by $x_{1} / x_{1}$ is positive. It is because that is directly implied by product 1's viability condition in equation (19). We thus have proved Proposition 2.

For a two-product monopolist to be able to credibly sell high quality requires that the consumer's value for high quality for product $2, v_{2}\left(1+\theta_{2}\right)$, be at least as high as the $\tilde{p_{2}}$ in equation (25). This will be possible for some parameter values even when high quality is not viable for a single-product monopoly.

What makes umbrella pricing helpful is first the lack of viability of high quality for product 2 . If high quality is already viable in market 2 , then the price immediately rises to the reservation price of high quality, $p_{2}=\left(1+\theta_{2}\right) v_{2}$, and nothing further can be done by umbrella pricing. If high quality is not viable for product 2 , then umbrella pricing can help. Equation (25) tells us that it is particularly likely to help if $\theta_{1}$, and $x_{1}$ are high relative to the other parameter values, and if $r$ and $\gamma_{1}$ are low. In words, what makes umbrella pricing most useful is when high quality is particularly important to product 1 and its market is large, and when the discount rate and the cost of high quality are low. Then, the total profit from selling highquality product 1 is particularly high relative to profits from low quality, removing the temptation to to sacrifice that profit for the one-time gain from cheating. Product 1's profit can be used as a hostage to ensure that the two-product monopolist does not cheat and sell low quality for product 2 .

A peculiar feature of umbrella branding is that it not only makes product $2 \mathrm{vi}$ - 
able; it does so without requiring the firm to sacrifice any profits whatsoever from product 1 . Only the threat of losing those profits, an out-of-equilibrium event, is necessary. After extending its umbrella to product 2 , the firm can still sell product 1 at the monopoly price of $p_{1}=\left(1+\theta_{1}\right) v_{1}$ - the extension is costless.

This has been in the context where the firm does not face competition in the market for the unviable product 2. The next task is to see what happens when there is competition in one or both markets. We will start with competition in both markets.

\section{Umbrella Pricing in a Competitive Industry}

Now let the industry be competitive: more than one firm can offer each product, and they engage in Bertrand competition. A firm can sell either one or both of the two products.

If high quality is viable for both products, umbrella beliefs have no effect. A firm's post-entry profit from producing both at high quality is

$$
\frac{\left(p_{1}-\left(1+\gamma_{1}\right) c_{1}\right) x_{1}}{r}+\frac{\left(p_{2}-\left(1+\gamma_{2}\right)\right) x_{2}}{r}
$$

compared with a deviation payoff of

$$
\frac{\left(p_{2}-\left(1+\gamma_{2}\right) c_{2}\right) x_{2}}{1+r}+\frac{\left(p_{2}-\left(1+\gamma_{2}\right) c_{2}\right) x_{2}}{1+r}
$$

These are equated by the same values of $p_{1}^{*}$ and $p_{2}^{*}$ as when firms sell individual products. Note that whether low quality is viable or not is unimportant to the deviation payoff, since high quality yields greater consumer surplus and a firm that is believed to have low quality will attract no customers even if it charge a price equal to marginal cost.

The two payoffs are also equated by many other price pairs. Would any of those support an equilibrium? No. Any other price pair would require not just 
umbrella beliefs but also that $p_{1}>p_{1}^{*}$ and $p_{2}<p_{2}^{*}$ ( or $p_{1}<p_{1}^{*}$ and $p_{2}>p_{2}^{*}$ ), because consumers would have to believe that the firm would be making so much extra profit on the "overpriced" product that it would not deviate to low quality because of the low price on the "underpriced" product. But then some other firm could offer to sell just product 1 at $p=p_{1}^{*}$ and would steal away the entire market from the umbrella-branding firm - which would then lose its credibility for producing high quality in its low-priced market, product 2 . So there is no advantage to umbrella pricing.

As a result, if product 1 is viable but product 2 is unviable, umbrella pricing will not extend viability to product 2, unlike in a monopoly market. Firms do not have "redundant" profits from product 1 that they can put at risk to give themselves an incentive for high quality from product 2 .

Put differently, in a competitive market, the incentive compatibility constraint for high quality is binding, unlike in the monopoly case. Hence, there is no slack in the incentive compatibility constraint for product 1 that could be used to create an incentive for high quality for product 2 . Thus we have Proposition 3.

Proposition 3: A competitive industry made up of firms selling two products cannot maintain high quality if an industry of firms selling one product each could not.

One caveat regarding Proposition 3 is that it does depend crucially on competitive firms competing the price down to the Klein-Leffler levels in equilibrium. This may seem obvious under Bertrand competition, but it entails the restriction on out-of-equilibrium beliefs stated earlier. There exist perfect bayesian equilibria in which competitive firms charges prices higher than the Klein-Leffler prices because any firm that tried to undercut the others - which is out-of-equilibrium behavior- is believed by consumers to have low quality. The belief that a particular price level above $p^{*}$ is the minimum one necessary for high quality is arbitrary, but if we started from that equilibrium then competitive firms would have "extra" profits beyond those necessary to support high quality in that product, and they could use some of the slack in that incentive compatibility constraint to charge less 
than the Klein-Leffler price in the market for a nonviable product.

\section{Leveraging Monopoly Power Using Umbrella Pricing}

What if all products are viable but some are sold competitively and some by monopolies? We will see that a monopolist will be able to leverage his monopoly to take over a competitive product.

Let there be 2 monopolies and 3 products, all strictly viable, with demand and cost parameters $v_{i}, \gamma_{i}, \theta_{i}, c_{i}$, and $x_{i}, i=1,2,3$. Monopoly 1 and monopoly 2 are the only possible producers of products 1 and 2, while product 3 can be produced at the same cost by both those two firms and by many other competitive firms. This will allow us compare not just competition between a competitive industry and a monopoly but between two monopolies. We will assume, to reduce clutter, that $v_{1}<c_{1}$ and $v_{2}<c_{2}$ ), so low quality is not viable for products 1 and 2 .

The quality-guaranteeing price for product 3 will be different for monopoly 1 , monopoly 2, and the competitive firms. Thus, let us clarify the out-of-equilibrium beliefs being assumed. On observing an out-of-equilibrium price, consumers believe a firm chose low quality if its price is below the quality-guaranteeing price $p^{*}$ for that firm and high quality otherwise.

If the monopolies are not allowed to sell product 3, the market prices are, from (3),

$$
\begin{aligned}
& p_{1}=\left(1+\theta_{1}\right) v_{1} \\
& p_{2}=\left(1+\theta_{2}\right) v_{2} \\
& p_{3}=p_{3}^{*}(\text { competitive })=c_{3}+(1+r) \gamma_{3} c_{3}
\end{aligned}
$$

What if monopoly 1 , but not monopoly 2 is allowed to sell product 3 ? At what price $p_{3}^{*}(M o n .1)$ would monopoly 1 be indifferent between high and low quality for product 3 ? This would, if there are umbrella beliefs, equate the profit from high 
quality,

$$
\frac{\left(\left(1+\theta_{1}\right) v_{1}-\left(1+\gamma_{1}\right) c_{1}\right) x_{1}}{r}+\frac{\left(p_{3}-\left(1+\gamma_{3}\right) c_{3}\right) x_{3}}{r}
$$

to the profit from low quality,

$$
\frac{\left(\left(1+\theta_{1}\right) v_{1}-c_{1}\right) x_{1}}{1+r}+\frac{\left(p_{3}-c_{3}\right) x_{3}}{1+r} .
$$

Equating the last two expressions and solving this for $p_{3}$ yields

$$
\begin{aligned}
p_{3}^{*}(\text { Mon. } 1) & =\left(1+\gamma_{3}\right) c_{3}+r \gamma_{3} c_{3}-\frac{\left[\left(1+\theta_{1}\right) v_{1}-\left(1+(1+r) \gamma_{1}\right) c_{1}\right] x_{1}}{x_{3}} \\
& =p_{3}^{*}-\frac{\left[\left(1+\theta_{1}\right) v_{1}-\left(1+(1+r) \gamma_{1}\right) c_{1}\right] x_{1}}{x_{3}}
\end{aligned}
$$

Clearly, $p_{3}^{*}$ (Mon. 1$)<p_{3}^{*}$ (competitive). Thus, with monopoly 1 selling not just product 1 but also selling product 3 in its competitive market, the competitive firms would be undercut by the monopoly. In equilibrium, monopoly 1 would capture the entire market, by charging the competitive Klein-Leffler price, $p_{3}^{*}$ (competitive). This, with consumers all choosing firm 1 despite its only tying the price of other firms, is the only subgame perfect equilibrium, since we cannot have an equilibrium in which firm 1 charges a smallest number $\epsilon$ less than $p_{3}^{*}$ (competitive) to make consumers strictly desirous of buying from monopoly 1 .

Now open up product 3 to sales by monopoly 2. We know that monopoly 2's Klein-Leffler price for good 3 would, by the same reasoning as for monopoly 1, be $p_{3}^{*}($ Mon. 2$)<p_{3}^{*}$. Suppose, without loss of generality, that $p_{3}^{*}\left(\right.$ Mon.2) $<p_{3}^{*}($ Mon.1), as would be the case if the cost of product 2 were lower, or its reservation price higher, or its market bigger. Then in the price competition between monopolies 1 and 2, monopoly 2 will capture the entire market for product 3 , at price $p_{3}^{*}(M o n .1)$, the price below which monopoly 1 cannot cut without losing the consumer's belief that it has high quality. The upshot of monopolies 1 and 2 leveraging their market power in other markets will be that the price fall for product 3 , benefit- 
ing consumers. Prices would also fall if it were monopoly 1 that had the lowest leveraged price, or even if both firms had the same leveraged price since then their competition would drive it down to that level and they would split the sales and profit.

Thus, we have proved Proposition 4.

Proposition 4: Suppose one product can be produced by only one firm but a second product can be produced by many firms. If the monopoly is allowed to produce both products, it will capture both markets. If a firm with a monopoly on some third product also tries to sell in the competitive market, competition between the two monopolies will result in monopoly leveraging that helps consumers.

Note that Proposition 4 does depend on strict viability of high quality for both monopolies in their original markets. That is what provides the unused incentive capacity, the "excess hostages" that can be used to undercut firms in the competitive market.

Anti-trust law has long struggled with whether to worry about the leveraging of monopoly in one market to acquire a monopoly in a second market. Here, that is exactly what happens. In our setting, however, the leveraging does not result from bundling, predatory pricing, exclusive dealing contracts, or production economies. Rather, it results from the ability of the monopolist to use its profits in its monopoly market as a bond for good behavior in the competitive market. This could be seen as an economy of scope, but it is a demand-side phenomenon, not a supply-side one.

This kind of monopoly leveraging is distinguishable from improper leveraging in two ways. First, it does not involve any kind of complex contract that ties the two markets together, unlike bundling or exclusive dealing. Second, the monopoly does not charge less than the cost of the competitive firms. Instead, it outcompetes them because consumers feel safer paying a low price to the monopolist than to the competitive firms because even at the lower price the monopoly still has incentive 
to maintain its reputation across markets.

The intuition is easy to extend to a market in which high quality is not viable but in which consumers are willing to buy even low quality if necessary $(v>c)$. In that case, if its reputation in the initially monopolized market is a sufficiently valuable bond, an umbrella-pricing monopolist could enter with high quality and capture the market even if its price were higher than what the competitive firms were charging for low quality.

The introduction mentioned the tying model of Whinston (1990), which has interesting similarities and differences from the reputation leveraging in the present paper. Imagine that goods $A$ and $B$ each have consumer reservation prices of 8 and are monopolized by a firm that has marginal cost of 5 for each of them. A new firm with a marginal cost of 3 appears which is able to enter the market for good B if it pays an entry cost of 1 . If the monopolist sells the two goods separately, the new firm will enter market $B$ and drive out the monopolist. If the monopoly commits to tying sales of $A$ and $B$, however and charges a price of 16 for the bundle instead of 8 for each, it is safe from entry. The reason is that if the new firm enters, the monopolist would be willing to let the bundle's price drop to 10.9 , leaving consumers with a surplus of 5.1 which is greater than the 5 they could get by buying only good B from the new firm. The monopolist is willing to do this, because his payoff is still .9. better than the 0 he would get by losing the sale. By tying the two products, the monopolist has put his profits from good A at risk, effectively increasing his aggressiveness in market B.

The Whinston model and the umbrella model are alike in that the monopolist purposely puts its monopoly profits at risk in order to make profits in the market for a second good which is neither a substitute nor a complement. In the Whinston model, however, the monopolist succeeds because it has increased potential price-cutting off the equilibrium path, inefficiently excluding rivals and hurting consumers. In the umbrella model, the monopolist succeeds because it has reduced potential quality-cheating off the equilibrium path, and done it in a way that competitive firms cannot match. It captures the market because consumers 
get more surplus from its high quality than from the rival's. Furthermore, while in the Whinston model the success of the leverage depends upon driving out competitors, in the umbrella model that is incidental, and no fixed cost is necessary to prevent competitors from returning to the market.

\section{Concluding Remarks}

When product quality is a problem of moral hazard rather than adverse selection, the problem is one of incentive compatibility constraints. The seller must be able to earn enough from future sales of high quality to prefer that to a deviation to low quality and a higher profit in the current period. This requires a price above the marginal cost of high quality, and if the quality-incentivizing price is too high, consumers will prefer to buy low quality at a low price or not to buy at all; the incentive compatibility constraint for high quality cannot be satisfied with positive sales. Even in the single-product case, it may be possible to relax the incentive compatibility constraint by intentionally reducing the value of low quality or, if the seller is a monopoly, by reducing the profitability of low-quality sales by opening up low-quality production to competing firms. Selling more than one product-umbrella branding - is another potential way to relax the constraint. This can be done only by a seller with a monopoly in one product, however, because the advantage of umbrella branding is in using some of the slack in the incentive compatibility constraint of a monopoly seller, who would sell at a high price anyway, even without the need to raise the price above marginal cost to incentivize quality. A competitive market may have firms with valuable reputations for high quality in individual products, but they cannot leverage the reputation they have in one product over to another product. This is a distinctive feature of quality as a moral hazard problem, relying as it does on the incentive compatibility constraints being binding. A firm with a monopoly on one product can not only extend its reputation umbrella to other products, but by so doing can outcompete competitive firms producing that product. This is not the monopoly leveraging of bundling models - where the puzzle is why the monopoly is willing to lose profits on one product in order to capture the market for another. Rather, it is the ability 
of the monopoly to use its profits in the monopolized market as a bond for high quality in the open market. This ability is socially useful, allowing it to produce a high-quality product the competitive market cannot or to provide it at a lower price. Hence, although this reputation leveraging may hurt the competitive firms that used to sell the product at a quality-ensuring premium above cost, it increases social welfare, and will actually help consumers if competition among monopoly leveragers results in a lower price for the formerly competitive high-quality product. 


\section{References}

Andersson, Frederik (2002) "Pooling Reputations," International Journal of Industrial Organization, 20(5): 715-730 (May 2002).

Bernheim, B. Douglas \& Michael D. Whinston (1990) “Multimarket Contact and Collusive Behavior," The RAND Journal of Economics, 21(1): 1-26 (Spring 1990).

Cabral, Luis M. B. (2000) "Stretching Firm and Brand Reputation," The RAND Journal of Economics, 31(4): 658-673 (Winter 2000).

Cabral, Luis M. B. (2009) “Umbrella Branding with Imperfect Observability and Moral Hazard," International Journal of Industrial Organization, 27: 206-213 (2009).

Cai, Hongbin, \& Ichiro Obara (2006) "Firm Reputation and Horizontal Integration," Rand Journal of Economics, 40:341-364 (2009).

Choi, Chong Ju \& Carlo Scarpa (1992) “Credible Spatial Preemption through Reputation Extension," International Journal of Industrial Organization, 10(3): 439447 (September 1992).

Choi, Jay Pil (1998) "Brand Extension as Informational Leverage," The Review of Economic Studies, 65(4): 655-669 (October 1998).

Choi, Jay Pil (2003) “Bundling New Products with Old to Signal Quality, with Application to the Sequencing of New Products," International Journal of Industrial Organization, 21: 1179-1200 (October 2003).

Dana, James \& Kathryn Spier (2009) “Bundling and Product Reputation," Harvard Law School Public Law and Legal Theory Working Paper Series, Paper No. 09-60.

Deneckere \& McAfee (1996) “Damaged Goods," Journal of Economics \& Management Strategy, 5(2): 149-174 (June 1996). 
Hakenes, Hendrik \& Martin Peitz (2008) "Umbrella Branding and the Provision of Quality," International Journal of Industrial Organization, 26(2): 546-556 (March 2008).

Klein, Benjamin \& Keith Leffler (1981) "The Role of Market Forces in Assuring Contractual Performance," Journal of Political Economy 89: 615-641.

Miklos-Thal, Jeanine (2010) "Linking Reputations through Umbrella Branding," working paper, William E. Simon Graduate School of Business Administration, University of Rochester (August 30, 2010).

Rey, Patrick, Paul Seabright \& Jean Tirole (2001) "The Activities of a Monopoly Firm in Adjacent Competitive Markets: Economic Consequences and Implications for Competition Policy," http://time.dufe.edu.cn/jingjiwencong/waiwenziliao/ tirole018.pdf.

Rey, Patrick \& Jean Tirole (2007) "A Primer on Foreclosure," Handbook of Industrial Organization III, edited by Mark Armstrong and Robert Porter, Elsevier, urlhttp:/ /idei.fr/doc/by/tirole/primer.pdf (2007).

Rotemberg, Julio J. (2010) “Quality Provision, Expected Firm Altruism and Brand Extensions,"Working Paper 15635, National Bureau of Economic Research (January 2010).

Shapiro, Carl (1983) "Premiums of High Quality Products as Returns to Reputations," Quarterly Journal of Economics, 98: 659-679.

Swaminathan, Vanitha, Richard J. Fox \& Srinivas K. Reddy, "The Impact of Brand Extension Introduction on Choice," Journal of Marketing, 65: 1-15 (October 2001).

Wernerfelt, Birger (1988) "Umbrella Branding as a Signal of New Product Quality: An Example of Signalling by Posting a Bond," RAND Journal of Economics, 19(3): 458-466 (Autumn 1988). 
Whinston, Michael D. (1990) "Tying, Foreclosure, and Exclusion," The American Economic Review, 80(4): 837-859 (September 1990). 